\title{
The effect of raw vegetable and fruit intake on thyroid cancer risk among women: a case-control study in South Korea
}

\author{
Su Kyoung Jung ${ }^{1}$, Kirang Kim ${ }^{1,2}$, Kyung Tae ${ }^{3}$, Gu Kong ${ }^{4}$ and Mi Kyung Kim ${ }^{1 *}$ \\ ${ }^{1}$ Department of Preventive Medicine, College of Medicine, Hanyang University, Medical School Building A-Room 512, \\ 17 Haengdang Dong, Sungdong Gu, Seoul 133-791, Republic of Korea \\ ${ }^{2}$ Division of Health and Nutrition Survey, Korea Centers for Disease Control and Prevention, Cheongwon 363-951, \\ Republic of Korea \\ ${ }^{3}$ Department of Otolaryngology, College of Medicine, Hanyang University, Seoul, Republic of Korea \\ ${ }^{4}$ Department of Pathology, College of Medicine, Hanyang University, Seoul, Republic of Korea
}

(Submitted 1 September 2011 - Final revision received 27 January 2012 - Accepted 27 January 2012 - First published online 28 March 2012)

\begin{abstract}
Thyroid cancer is the most common cancer among Korean women. However, there are few data on dietary factors related to thyroid cancer risk. The objective of the present study was to evaluate the association between raw vegetables and fruits intake and thyroid cancer in a case-control study. We included 111 histologically confirmed malignant thyroid cancer cases and 115 benign cases. Controls who did not have nodules in thyroid ultrasonography were matched to cases by age ( \pm 2 years). Food and nutrient intakes were estimated using a quantitative FFQ with 121 items. Conditional logistic regression analysis was used to obtain OR and corresponding $95 \%$ CI. The intake of total vegetables was not associated with malignant thyroid cancer, but inversely associated with benign cases. High raw vegetable intake was inversely associated with thyroid cancer risk both in malignant and benign cases ( $P$ for trend $=0 \cdot 01$ in both malignant and benign cases). Among fruits, persimmon intake had an inverse association with thyroid cancer risk in both malignant and benign cases ( $P$ for trend $=0.06$ in malignant cases; $P$ for trend $=0.01$ in benign cases) and tangerine intake had an inverse association in malignant cases $(P$ for trend=0.03). The frequency of consumption of raw vegetables and persimmon also had a consistent inverse association in both malignant and benign cases. These results suggest that high consumption of raw vegetables, persimmons and tangerines may decrease thyroid cancer risk and help prevent early-stage thyroid cancer.
\end{abstract}

Key words: Vegetables: Persimmons: Tangerines: Thyroid cancer: Case-control study

Thyroid cancer is the most common tumour type of the endocrine system $^{(1)}$. Since the 1970 s, thyroid cancer incidence rates have increased worldwide ${ }^{(1)}$. In contrast to Western countries, where breast cancer is the most common cancer type in women, thyroid cancer is the most common cancer type in adult Korean women ${ }^{(2,3)}$. The age-standardised incidence rate of thyroid cancer in Korean women $(86 \cdot 1 / 100000)$ is higher than that of other countries and worldwide (22.3/100000 for the USA, 11.5/100000 for Europe, 8.3/ 100000 for Japan, 3.0/100 000 for China and 6.6/100 000 worldwide $)^{(2)}$. Furthermore, the incidence of this cancer type in Korean women has increased remarkably over time from $11 \cdot 9 / 100000$ in 1999 to $80 \cdot 2 / 100000$ in $2008^{(3)}$.

The best-established risk factors for thyroid cancer are exposure to radiation ${ }^{(4)}$ and a history of benign thyroid nodules or adenomas ${ }^{(5)}$. Exposure to radiation and benign thyroid nodules or adenomas may induce thyroid cancer through gene rearrangements ${ }^{(6)}$ or mutations ${ }^{(7)}$. However, to our knowledge, only one cohort study reported some possible risk factors such as family history of cancer, BMI and hormonal factors for benign thyroid nodules ${ }^{(8)}$, while little is known about lifestyle factors that may increase or decrease the risk of benign thyroid nodules or adenomas. Some dietary factors have also been reported to be related to thyroid cancer risk including fruit intake ${ }^{(9)}$, vegetable intake ${ }^{(9-12)}$, cruciferous vegetable intake $\mathrm{e}^{(4,10-13)}$, fish intake ${ }^{(12-16)}$, glycaemic index, glycaemic load ${ }^{(17)}$, micronutrients ${ }^{(18)}$ iodine $^{(13,15)}$ and nitrate ${ }^{(19,20)}$. Among dietary factors, fruits and vegetables have been reported to have protective effects against many different cancers $^{(21,22)}$. Some epidemiological studies have investigated the effect of fruit and vegetable intake on thyroid cancer risk.

Abbreviation: KNHANES, Korean National Health and Nutrition Survey.

*Corresponding author: M. K. Kim, fax +82 22293 0660, email kmkkim@hanyang.ac.kr 
However, those studies were conducted primarily in Western countries $^{(4,9-11)}$ and their findings were inconsistent ${ }^{(4)}$.

Vegetables can be consumed raw, cooked or pickled; these latter two procedures may destroy the antioxidants present in raw vegetables ${ }^{(23-26)}$. Thus, the effect of raw vegetables on cancer risk might be masked if total vegetable consumption, including all raw, cooked and pickled vegetables, is examined. Nevertheless, previous studies have not determined the effect of raw vegetable consumption on cancer risk separately, except for a Greek study that reported an inverse association between raw vegetable dietary pattern and thyroid cancer ${ }^{(9)}$.

Although the effects of fruit intake on thyroid cancer risk have been investigated in a few previous studies, inconsistent results were reported. This could be because different fruits have different effects on different cancer types. A Norwegian study reported an increased risk of thyroid cancer with citrus fruit consumption, but no association with apple intake $^{(10)}$. A Greek study reported that fresh tomatoes and lemons may reduce thyroid cancer risk ( $P$ for trend $=0.002$ for tomatoes; $P$ for trend=0.001 for lemons). Our objective in the present study was to investigate the association between total and raw vegetable intake and fruit intake on benign and malignant thyroid cancer risk in a Korean population.

\section{Materials and methods}

\section{Cases and controls}

From June 2008 to June 2010, cases and controls were recruited at Hanyang University Medical Center in Seoul, South Korea. All participants were women between the ages of 20 and 70 years. All potential subjects were examined by ultrasonography to confirm the presence of thyroid cancer.

Malignant cases were diagnosed by fine needle aspiration biopsy and ultrasonography. About $90 \%$ of malignant cases were papillary carcinoma. Benign cases were subjects who had benign nodules or adenomas in ultrasonography and/or fine needle aspiration biopsy. We included 111 histologically confirmed malignant cases and 115 benign cases in this study.

Subjects were excluded from the study if they had any history of cancer (ten cases), or an estimated total energy intake $<2093 \mathrm{~kJ} / \mathrm{d}(500 \mathrm{kcal} / \mathrm{d})$ or $>16744 \mathrm{~kJ} / \mathrm{d}(4000 \mathrm{kcal} / \mathrm{d})$ (eighteen cases and one control). Controls were patients who visited the otolaryngology or orthopaedic surgery departments of the same hospital. Patients with hormone-related diseases, abnormal thyroid hormone levels (thyroxine, thyroid-stimulating hormone) or thyroid nodules found by ultrasonography were excluded. Cases and controls were matched by their age (within 2 years) (111 pairs of malignant cases and controls and 115 pairs of benign cases and controls). All interviews were conducted in the hospital and the response rates for malignant and benign cases combined and controls were 70.4 and $41.0 \%$, respectively. This study was conducted according to the guidelines laid down in the Declaration of Helsinki and all procedures involving human subjects were approved by the Institutional Review Board of
Hanyang University Medical Center. Written informed consent was obtained from all participants.

\section{Data collection}

Cases and controls were interviewed using questionnaires to determine patients' general characteristics, menstrual and reproductive history, family history of thyroid cancer, smoking and drinking habits, intake of multivitamins and average time spent exercising

Dietary data were collected using a quantitative FFQ, modified from the validated $\mathrm{FFQ}^{(27)}$, with visual aids such as food photographs and models to demonstrate item-specific units. Kim et $a l{ }^{(27)}$ evaluated the validity and reproducibility of semiquantitative FFQ by administering it twice at an interval of 2 years and comparing it with four or five $24 \mathrm{~h}$ recalls collected at intervals of 3 months. The Pearson's correlation coefficients between energy-adjusted nutrient intakes averaged 0.44 on the first questionnaire $v .24 \mathrm{~h}$ recalls and 0.37 on the second questionnaire $v .24 \mathrm{~h}$ recalls for fourteen nutrients (protein, fat, carbohydrate, fibre, Ca, P, Fe, Na, K, vitamin $\mathrm{A}$, thiamin, riboflavin, niacin and ascorbic acid). The reproducibility of this FFQ determined by the correlation of the nutrient intakes was greater than 0.5 . Regarding reliability of the modified FFQ, using our data for controls, the Cronbach's $\alpha$ was 0.78 for food frequency and 0.87 for its portion size.

Subjects were asked by trained interviewers to recall their usual intake of 121 food items over a period of 12 months beginning from 3 years before the time of the interview ${ }^{(28)}$. Portion sizes were open-ended questions and standard units were used for all food items. All frequencies were standardised into 'times per d' by using the conversion factors $30 \cdot 4 \mathrm{~d} /$ month and $4.3 \mathrm{~d} /$ week. Daily food intake was calculated using the standardised frequency per $\mathrm{d}$ and the amount of food per standard unit. Daily nutrient and energy intake were estimated using the daily food intake and recipe and nutrient database ${ }^{(29)}$. Nutrient intakes were adjusted for total energy intake by the residual method to avoid bias due to the simple relationship between nutrient intake and total energy intake ${ }^{(28)}$. Total vegetable intake was estimated by summing the daily consumption of pickled vegetables (cabbage kimchi, radish kimchi, watery radish kimchi, cucumber kimchi, sesame leaf kimchi and jangajji), raw vegetables (lettuce, Korean cabbage, cabbage, cucumber, pepper, carrot, sesame leaf, onion, radish, crown daisy, water dropwort, chicory, broccoli, celery and garlic), cooked vegetables (soyabean sprouts, mungbean sprouts, spinach, eggplant and bracken), mushrooms and seaweeds. Total fruit intake was estimated by totalling the daily intake of fourteen fruits (persimmon, tangerine, orange, kiwi, melon, grape, strawberry, watermelon, pear, apple, banana, peach, tomato and fruit juice).

\section{Statistical analyses}

Cases and controls were compared using the Wilcoxon signed rank test for continuous variables and the McNemar test for categorical variables. Data were analysed according to 
quartiles of daily intake $(\mathrm{g} / \mathrm{d})$ and average consumption frequency (times/week) of total vegetables, raw vegetables, total fruits and all single fruits. Among single fruits, only fruits significantly associated with malignant cancer or benign thyroid disease are presented in the tables. The OR and corresponding $95 \%$ CI were obtained using conditional logistic regression analysis. The general linear model and CochranMantel-Haenszel analysis were used to assess potential confounders among controls. Trend tests were conducted by treating the median values of each quartile of daily fruit and vegetable intake or the average consumption frequency of the specific fruit or vegetable as continuous values in each of the models. Variables that were significantly different between cases and controls and which showed significant linear trends across quartiles of daily intake of total vegetables, raw vegetables, total fruits, persimmons and tangerines were considered as potential confounders and adjusted in the analyses. Antioxidants such as vitamin $\mathrm{C}, \beta$-carotene, and folate, which were highly correlated with fruit and vegetable intake $\left(r_{\mathrm{p}}>0.40\right)$, were not included in multiple logistic regression models as potential confounders. All multiple logistic regression models included parity (yes/no), energy (quartile) for malignant pair analyses and energy (quartile) for benign pair analyses. Additionally, $\mathrm{Na}$ (quartile) was added in the total vegetable model, whereas $\mathrm{Na}$ (quartile) and vitamin $\mathrm{E}$ (quartile) were added in the raw vegetable model, and age at menarche (years) was added in the persimmon model. Parity (yes/no) was added in the tangerine model. Statistical analyses were conducted using SAS (version 9.1) software.

\section{Results}

Table 1 shows the general characteristics of the cases and controls. The average ages of malignant cases and controls were 45.9 and 45.2 years, respectively, and those of benign cases and controls were 46.8 and 46.5 years, respectively. Parity was significantly higher in malignant cases than controls. Daily intake of raw vegetables was higher in controls than in malignant cases $(34.1 \mathrm{~g} / \mathrm{d}$ for malignant cases $v .47 .7 \mathrm{~g} / \mathrm{d}$ for controls). Daily intake of total vegetables and persimmons were higher in controls than benign cases $(240.7 \mathrm{~g} / \mathrm{d}$ for benign cases $v$. $268.9 \mathrm{~g} / \mathrm{d}$ for controls in total vegetables

Table 1. General characteristics of the study subjects with and without thyroid cancer $†$

(Mean values and standard deviations or proportions)

\begin{tabular}{|c|c|c|c|c|c|c|c|c|c|c|}
\hline \multirow[b]{3}{*}{ Characteristics } & \multicolumn{4}{|c|}{ Malignant } & \multirow[b]{3}{*}{$P^{*}$} & \multicolumn{4}{|c|}{ Benign } & \multirow[b]{3}{*}{$P^{*}$} \\
\hline & \multicolumn{2}{|c|}{ Cases ( $n 111)$} & \multicolumn{2}{|c|}{ Controls ( $n$ 111) } & & \multicolumn{2}{|c|}{ Cases $(n 115)$} & \multicolumn{2}{|c|}{ Controls ( $n 115)$} & \\
\hline & Mean & SD & Mean & SD & & Mean & SD & Mean & SD & \\
\hline Age (years) & $45 \cdot 9$ & $10 \cdot 8$ & $45 \cdot 2$ & $10 \cdot 6$ & $\mathrm{~N} / \mathrm{A}$ & $46 \cdot 8$ & $10 \cdot 1$ & $46 \cdot 5$ & $10 \cdot 5$ & $\mathrm{~N} / \mathrm{A}$ \\
\hline Education (years) & $12 \cdot 3$ & 3.9 & $12 \cdot 0$ & $3 \cdot 7$ & 0.537 & $12 \cdot 3$ & 3.6 & 11.7 & 3.5 & 0.156 \\
\hline BMI $\left(\mathrm{kg} / \mathrm{m}^{2}\right)$ & 23.4 & $3 \cdot 4$ & $23 \cdot 5$ & $3 \cdot 6$ & 0.930 & $23 \cdot 4$ & $2 \cdot 8$ & 23.4 & $3 \cdot 4$ & 0.980 \\
\hline Children $(n)$ & $2 \cdot 0$ & 0.9 & 1.8 & $1 \cdot 2$ & 0.134 & 1.9 & 1.0 & 1.9 & 1.2 & 0.246 \\
\hline Age at menarche (years) & $14 \cdot 6$ & $2 \cdot 0$ & $14 \cdot 6$ & 1.9 & 0.905 & $14 \cdot 6$ & $1 \cdot 8$ & $14 \cdot 7$ & 1.9 & 0.647 \\
\hline Age at first birth (years) & $26 \cdot 0$ & $3 \cdot 6$ & $26 \cdot 1$ & 3.9 & 0.804 & $25 \cdot 4$ & $3 \cdot 1$ & $25 \cdot 7$ & $3 \cdot 7$ & 0.559 \\
\hline Age at menopause (years) & $49 \cdot 6$ & 4.6 & 49.2 & $5 \cdot 1$ & 0.701 & $49 \cdot 3$ & $5 \cdot 0$ & $49 \cdot 6$ & $4 \cdot 3$ & 0.567 \\
\hline \multicolumn{11}{|l|}{ Dietary intake } \\
\hline Energy $(\mathrm{kJ} / \mathrm{d})$ & $8401 \cdot 6$ & $704 \cdot 2$ & $8567 \cdot 7$ & 681.1 & 0.772 & $8561 \cdot 0$ & 631.2 & $8332 \cdot 1$ & $651 \cdot 2$ & 0.391 \\
\hline Carbohydrate (g/d) & 304.4 & $41 \cdot 8$ & $307 \cdot 0$ & $44 \cdot 8$ & 0.691 & $305 \cdot 7$ & $44 \cdot 0$ & $309 \cdot 3$ & $42 \cdot 6$ & 0.596 \\
\hline Fibre $(\mathrm{g} / \mathrm{d})$ & $8 \cdot 1$ & 2.5 & 8.3 & $2 \cdot 8$ & 0.811 & $8 \cdot 1$ & 2.9 & 8.6 & $3 \cdot 3$ & 0.250 \\
\hline$\beta$-Carotene $(\mu \mathrm{g} / \mathrm{d})$ & $3660 \cdot 8$ & $1492 \cdot 6$ & $4130 \cdot 5$ & 3048.5 & 0.685 & 4098.5 & $4168 \cdot 2$ & $4405 \cdot 3$ & $4276 \cdot 8$ & 0.457 \\
\hline Vitamin C $(\mathrm{mg} / \mathrm{d})$ & 135.4 & $59 \cdot 3$ & 144.6 & 73.2 & 0.470 & $139 \cdot 3$ & $70 \cdot 7$ & 148.9 & 81.4 & 0.391 \\
\hline Folate $(\mu \mathrm{g} / \mathrm{d})$ & 267.5 & $83 \cdot 6$ & $270 \cdot 0$ & $102 \cdot 0$ & 0.979 & 259.0 & 85.5 & $276 \cdot 8$ & $120 \cdot 8$ & 0.341 \\
\hline Vitamin $E(m g / d)$ & $9 \cdot 2$ & $3 \cdot 2$ & $9 \cdot 0$ & $3 \cdot 7$ & 0.344 & $9 \cdot 6$ & 3.6 & $9 \cdot 1$ & $3 \cdot 8$ & 0.196 \\
\hline $\mathrm{Na}(\mathrm{mg} / \mathrm{d})$ & $4146 \cdot 7$ & $1301 \cdot 3$ & $4048 \cdot 7$ & $1435 \cdot 6$ & 0.599 & $3907 \cdot 8$ & $1447 \cdot 1$ & $4053 \cdot 7$ & $1506 \cdot 5$ & 0.400 \\
\hline Total vegetables $(\mathrm{g} / \mathrm{d})$ & 243.6 & 161.5 & $265 \cdot 1$ & $196 \cdot 3$ & 0.391 & 240.7 & $319 \cdot 2$ & 268.9 & $203 \cdot 3$ & 0.030 \\
\hline Raw vegetables (g/d) & $34 \cdot 1$ & $43 \cdot 0$ & $47 \cdot 7$ & 59.5 & 0.015 & $45 \cdot 0$ & $79 \cdot 9$ & $53 \cdot 2$ & $71 \cdot 8$ & 0.316 \\
\hline Total fruits $(g / d)$ & 297.4 & 243.5 & 331.0 & $291 \cdot 1$ & 0.418 & 347.7 & 341.1 & 323.8 & 287.4 & 0.598 \\
\hline Persimmon (g/d) & $14 \cdot 1$ & $34 \cdot 0$ & $18 \cdot 2$ & $37 \cdot 7$ & 0.063 & $14 \cdot 2$ & $40 \cdot 6$ & $19 \cdot 3$ & $37 \cdot 8$ & 0.036 \\
\hline Tangerine $(\mathrm{g} / \mathrm{d})$ & 38.6 & $62 \cdot 0$ & $46 \cdot 1$ & $66 \cdot 1$ & 0.103 & 44.8 & 52.4 & $44 \cdot 1$ & $65 \cdot 1$ & 0.688 \\
\hline Menopause women (\%) & \multicolumn{2}{|c|}{$46 \cdot 0$} & \multicolumn{2}{|c|}{$40 \cdot 5$} & 0.109 & \multicolumn{2}{|c|}{$47 \cdot 0$} & \multicolumn{2}{|c|}{$46 \cdot 1$} & 0.835 \\
\hline Family history of thyroid cancer (\%) & \multicolumn{2}{|c|}{$3 \cdot 6$} & \multicolumn{2}{|c|}{$2 \cdot 7$} & 0.706 & \multicolumn{2}{|c|}{1.7} & \multicolumn{2}{|c|}{$1 \cdot 7$} & 1.000 \\
\hline Current smoker (\%) & \multicolumn{2}{|c|}{0.9} & \multicolumn{2}{|c|}{4.5} & 0.103 & \multicolumn{2}{|c|}{4.4} & \multicolumn{2}{|c|}{4.4} & 1.000 \\
\hline Current alcohol drinker (\%) & \multicolumn{2}{|c|}{$34 \cdot 2$} & \multicolumn{2}{|c|}{40.5} & 0.274 & \multirow{2}{*}{\multicolumn{2}{|c|}{$40 \cdot 0$}} & \multicolumn{2}{|c|}{$42 \cdot 6$} & 0.686 \\
\hline Regular exercise (>22.5 MET-h/week, \%) & \multicolumn{2}{|c|}{$22 \cdot 5$} & & & 0.162 & & & & & 0.493 \\
\hline Multivitamin user (\%) & & & & & 0.182 & & & & & 1.000 \\
\hline Parity (\%) & & & & & 0.013 & & & & & 0.206 \\
\hline Oral contraceptive use (ever, \%) & & & & & 1.000 & & & & & 0.206 \\
\hline Breast-feeding (ever, \%) & & & & & 0.330 & & & & & 0.862 \\
\hline Used hormone compound (ever, \%) & & & & & 0.239 & & & & & 0.083 \\
\hline
\end{tabular}

$\mathrm{N} / \mathrm{A}$, not applicable; MET, metabolic equivalent.

* Wilcoxon signed rank test for continuous variables and McNemar test for categorical variables.

†All nutrient intakes are total energy-adjusted values. 
Table 2. Potential confounders according to quartile of intake of total vegetables and raw vegetables among controls †‡

\begin{tabular}{|c|c|c|c|c|c|c|c|c|c|c|}
\hline & \multicolumn{4}{|c|}{ Quartiles of daily total vegetable intake } & \multirow[b]{2}{*}{$P$ for trend* } & \multicolumn{4}{|c|}{ Quartiles of daily raw vegetable intake } & \multirow[b]{2}{*}{$P$ for trend ${ }^{*}$} \\
\hline & $1 \mathrm{st}$ & 2nd & 3rd & 4th & & 1st & 2nd & 3rd & 4th & \\
\hline Median (g) & 73.3 & $152 \cdot 4$ & 246.5 & $450 \cdot 1$ & & 4.7 & $18 \cdot 1$ & 34.8 & $79 \cdot 2$ & \\
\hline Age (years) & 41.8 & 43.9 & $48 \cdot 3$ & $46 \cdot 3$ & 0.158 & 40.5 & 43.9 & $48 \cdot 8$ & $45 \cdot 3$ & 0.250 \\
\hline Menopause women (\%) & 41.0 & $44 \cdot 3$ & $40 \cdot 2$ & $41 \cdot 6$ & 0.829 & 45.9 & $36 \cdot 1$ & $49 \cdot 2$ & 37.5 & 0.699 \\
\hline Education (years) & 11.5 & $12 \cdot 1$ & $12 \cdot 1$ & $12 \cdot 4$ & 0.241 & $11 \cdot 2$ & 11.9 & $12 \cdot 3$ & $12 \cdot 4$ & $0 \cdot 184$ \\
\hline $\mathrm{BMI}\left(\mathrm{kg} / \mathrm{m}^{2}\right)$ & 21.9 & $24 \cdot 3$ & 23.0 & $23 \cdot 8$ & 0.189 & $22 \cdot 8$ & $23 \cdot 6$ & 23.6 & $23 \cdot 1$ & 0.877 \\
\hline Family history of thyroid cancer (\%) & $10 \cdot 5$ & 4.7 & 0.0 & 0.0 & 0.064 & $2 \cdot 3$ & $4 \cdot 2$ & 0.0 & 1.7 & 0.510 \\
\hline Current smoker (\%) & 4.5 & 4.1 & 0.0 & 4.6 & 0.831 & 0.0 & $2 \cdot 8$ & $8 \cdot 2$ & 1.7 & 0.488 \\
\hline Current alcohol drinker (\%) & 35.5 & 39.1 & 49.1 & $40 \cdot 1$ & 0.817 & 31.9 & $42 \cdot 0$ & $37 \cdot 8$ & $47 \cdot 0$ & 0.464 \\
\hline Regular exercise (>22.5 MET-h/week, \%) & $20 \cdot 1$ & $13 \cdot 8$ & $12 \cdot 4$ & $16 \cdot 2$ & 0.717 & $16 \cdot 6$ & $11 \cdot 2$ & $19 \cdot 3$ & $12 \cdot 9$ & 0.914 \\
\hline Multivitamin user (\%) & $27 \cdot 7$ & $26 \cdot 1$ & 11.9 & $19 \cdot 2$ & 0.287 & $24 \cdot 0$ & $27 \cdot 2$ & 13.5 & $26 \cdot 4$ & 0.725 \\
\hline Parity (\%) & $80 \cdot 6$ & 82.5 & 90.7 & $81 \cdot 6$ & 0.796 & $84 \cdot 3$ & $78 \cdot 6$ & $76 \cdot 1$ & $90 \cdot 7$ & 0.286 \\
\hline Children $(n)$ & $1 \cdot 8$ & 1.9 & $2 \cdot 0$ & $1 \cdot 7$ & 0.645 & 1.9 & 1.8 & $1 \cdot 7$ & 1.9 & 0.485 \\
\hline Oral contraceptive use (ever, \%) & 9.9 & $17 \cdot 4$ & 37.8 & $21 \cdot 6$ & 0.356 & $15 \cdot 2$ & $16 \cdot 0$ & $18 \cdot 3$ & $25 \cdot 5$ & 0.360 \\
\hline Breast-feeding (ever, \%) & $75 \cdot 0$ & 49.4 & 83.1 & $72 \cdot 4$ & 0.317 & 69.9 & $64 \cdot 1$ & $69 \cdot 2$ & $76 \cdot 1$ & 0.399 \\
\hline Used hormone compound (ever, \%) & $25 \cdot 2$ & 21.8 & $10 \cdot 3$ & $18 \cdot 6$ & 0.272 & 33.7 & $18 \cdot 4$ & $15 \cdot 5$ & $16 \cdot 9$ & 0.356 \\
\hline Age at menarche (years) & $15 \cdot 1$ & $14 \cdot 0$ & $15 \cdot 0$ & $14 \cdot 2$ & $0 \cdot 161$ & $14 \cdot 4$ & $14 \cdot 8$ & 14.5 & 14.4 & 0.624 \\
\hline Age at first birth (years) & 24.9 & $26 \cdot 4$ & $26 \cdot 1$ & $26 \cdot 1$ & 0.482 & $25 \cdot 9$ & $25 \cdot 5$ & $26 \cdot 1$ & $26 \cdot 1$ & 0.631 \\
\hline Age at menopause (years) & $47 \cdot 9$ & 48.4 & 49.2 & 50.5 & 0.074 & 47.9 & 47.4 & $50 \cdot 2$ & 49.7 & 0.293 \\
\hline Energy intake $(\mathrm{kJ} / \mathrm{d})$ & $7499 \cdot 2$ & $8262 \cdot 6$ & $7724 \cdot 3$ & $9776 \cdot 1$ & 0.002 & $8068 \cdot 0$ & $7969 \cdot 2$ & $8474 \cdot 8$ & $9015 \cdot 6$ & 0.177 \\
\hline$\beta$-Carotene $(\mu \mathrm{g} / \mathrm{d})$ & $2459 \cdot 7$ & $3503 \cdot 8$ & $4151 \cdot 4$ & $6644 \cdot 8$ & $<0.0001$ & 2438.2 & $3267 \cdot 7$ & $3281 \cdot 1$ & $7452 \cdot 3$ & $<0.0001$ \\
\hline Vitamin C intake $(\mathrm{mg} / \mathrm{d})$ & $98 \cdot 1$ & 128.9 & $152 \cdot 6$ & $191 \cdot 7$ & $<0.0001$ & 100.5 & 124.0 & $141 \cdot 0$ & $197 \cdot 4$ & $<0.0001$ \\
\hline Folate intake $(\mu \mathrm{g} / \mathrm{d})$ & 185.9 & 235.8 & 285.9 & $360 \cdot 1$ & $<0.0001$ & $200 \cdot 0$ & $239 \cdot 3$ & 254.4 & 365.5 & $<0.0001$ \\
\hline Vitamin E intake (mg/d) & 8.3 & 8.6 & $9 \cdot 6$ & $9 \cdot 8$ & 0.090 & 6.7 & 8.4 & 8.8 & 11.3 & $<0.0001$ \\
\hline Na intake $(\mathrm{mg} / \mathrm{d})$ & $2587 \cdot 7$ & 3427.5 & $4385 \cdot 1$ & 5391.9 & $<0.0001$ & 3226.5 & $4026 \cdot 8$ & $3925 \cdot 6$ & $4775 \cdot 3$ & $<0.0001$ \\
\hline
\end{tabular}

MET, metabolic equivalent.

" $P$-values for trends were determined by the general linear model for continuous variables and by the Cochran-Mantel-Haenszel test for categorical variables.

† All results except median and age were adjusted for age, and all nutrient intakes are total energy-adjusted values.

$¥$ Values are expressed as mean or percentage according to quartile of fruit and vegetable intake. 
intake; $14.2 \mathrm{~g} / \mathrm{d}$ for benign cases $v .19 \cdot 3 \mathrm{~g} / \mathrm{d}$ for controls in persimmon intake). Daily intake of energy, carbohydrates, fibre, $\beta$-carotene, vitamin $\mathrm{C}$, folate, vitamin $\mathrm{E}, \mathrm{Na}$, total fruits and tangerines did not differ between cases and controls for either malignant pairs or benign pairs.

Potential confounding factors determined by using the quartiles of daily total vegetable and raw vegetable intake are shown in Table 2 . Dietary intake of $\beta$-carotene, vitamin $\mathrm{C}$, folate and $\mathrm{Na}$ increased across quartiles of total vegetable intake and quartiles of raw vegetable intake.

Potential confounding factors determined by using the quartiles of daily total fruit, persimmon and tangerine intake are shown in Table 3. Average age and age at menarche increased across quartiles of daily persimmon intake. Vitamin $C$ increased across quartiles of total fruit intake, persimmon intake and tangerine intake. Daily intake of $\beta$-carotene and folate increased across quartiles of total fruit intake.

The association between vegetable and fruit intake and thyroid cancer risk is shown in Table 4. Total vegetable intake was inversely associated with benign thyroid cancer risk (OR 0.42; 95\% CI 0.19, 0.91; $P$ for trend $=0.028$ in benign cases). After adjusting for potential confounders (energy intake and $\mathrm{Na}$ intake), the significant inverse association remained (OR $0.11 ; 95 \%$ CI $0.03,0.47 ; \quad P$ for trend $=0.003$ in benign cases). A significant inverse association between raw vegetable intake and thyroid cancer risk was found (OR 0.31; $95 \%$ CI 0.12, 0.79; $P$ for trend $=0.036$ in malignant cases and OR $0.56 ; 95 \%$ CI $0.27,1 \cdot 15 ; P$ for trend $=0.085$ in benign cases). The inverse association between raw vegetable intake and thyroid cancer risk remained (OR 0.20; 95\% CI $0.07,0.62 ; P$ for trend $=0.007$ in malignant cases and OR $0.28 ; 95 \%$ CI $0.10,0.76 ; P$ for trend $=0.007$ in benign cases) after adjusting for potential confounders (parity, energy intake, vitamin $\mathrm{E}$ intake and $\mathrm{Na}$ intake). An inverse association between thyroid cancer risk and persimmon intake was found in both malignant and benign cases (OR $0.39 ; 95 \%$ CI $0.17,0.88$ for the highest quartile; $P$ for trend $=0.037$ in malignant cases and OR $0 \cdot 35 ; 95 \%$ CI $0 \cdot 15$, 0.82 for the highest quartile; $P$ for trend $=0.016$ in benign cases). After adjusting for potential confounders, the significant inverse associations remained (OR 0.41;95\% CI $0 \cdot 17$, 0.96 for the highest quartile; $P$ for trend $=0.061$ in malignant cases and OR $0 \cdot 35 ; 95 \%$ CI $0 \cdot 15,0.83$ for the highest quartile; $P$ for trend $=0.014$ in benign cases). An inverse association between tangerine intake and malignant thyroid cancer risk was found after adjusting for potential confounders, but there was no significant association between daily tangerine intake and benign thyroid cancer risk (OR 0.34; 95\% CI $0.13,0.86$ for the highest quartile; $P$ for trend $=0.027$ in malignant cases). There were no associations between thyroid cancer risk and daily intake of total vegetables or total fruits in the present study.

The association between thyroid cancer risk and the average frequency of vegetable and fruit intake is shown in Table 5. There was a trend for an inverse association between thyroid cancer risk and the average frequency of raw vegetable intake in malignant and benign cases after adjusting for potential confounders. The frequency of raw vegetable intake was inversely associated with thyroid cancer risk (OR $0 \cdot 28$; $95 \%$ CI $0 \cdot 10,0.78$ for the highest quartile; $P$ for trend $=0.009$ in malignant cases and OR 0.38; $95 \%$ CI $0 \cdot 16$, 0.91 for the highest quartile; $P$ for trend $=0.043$ in benign cases). A high frequency of persimmon intake was inversely associated with thyroid cancer risk (OR 0.44; 95\% CI 0.20, 0.94 for the highest quartile; $P$ for trend $=0.040$ in malignant cases and OR $0 \cdot 35 ; 95 \%$ CI $0 \cdot 15,0 \cdot 81$ for the highest quartile; $P$ for trend $=0.017$ in benign cases). The inverse association between the average frequency of persimmon intake and thyroid cancer risk remained after adjusting for potential confounders (OR 0.44; $95 \%$ CI 0.20, 0.99 for the highest quartile; $P$ for trend $=0.060$ in malignant cases and OR 0.33; 95\% CI 0.14, 0.79 for the highest quartile; $P$ for trend $=0.014$ in benign cases). We did not find a significant association between thyroid cancer risk and the frequency of total vegetable intake, total fruit intake or tangerine intake. The additional adjustments for the risk factors reported in previous studies (education, family history of thyroid cancer, BMI, current smoker and current alcohol drinker) did not substantially change the results (data not shown).

\section{Discussion}

Given that the effects of vegetable and fruit intake on thyroid cancer risk have not been well characterised, we aimed to examine the association between vegetable and fruit intake and the risk of thyroid cancer. We found that consumption of raw vegetables, persimmons and tangerines had a significant protective effect against thyroid cancer. Raw vegetable and persimmon intake had a dose-response effect on both malignant cases and benign cases in terms of both frequency of consumption as well as amount consumed. The amount of tangerines consumed showed a dose-response association with malignant cases.

According to the fourth Korean National Health and Nutrition Survey (KNHANES 2007-9), the average intake of total vegetables and fruits by Korean women is $293.8 \mathrm{~g} / \mathrm{d}$ and $209.6 \mathrm{~g} / \mathrm{d}$, respectively. In the present study, the consumption of total vegetables by malignant cases and benign cases $(243.6 \mathrm{~g} / \mathrm{d}$ for malignant cases, $240.7 \mathrm{~g} / \mathrm{d}$ for benign cases and $270.5 \mathrm{~g} / \mathrm{d}$ for controls) was lower than that reported by KNHANES $(293.8 \mathrm{~g} / \mathrm{d})$. The total fruit intake of cases and controls ( $297.4 \mathrm{~g} / \mathrm{d}$ for malignant cases, $347.7 \mathrm{~g} / \mathrm{d}$ for benign cases and $325.4 \mathrm{~g} / \mathrm{d}$ for controls) was higher than that reported by KNHANES $(209.6 \mathrm{~g} / \mathrm{d})$. With regard to persimmon intake, cases and controls had a lower intake than that reported by KNHANES $(14.1 \mathrm{~g} / \mathrm{d}$ for malignant cases, $14.2 \mathrm{~g} / \mathrm{d}$ for benign cases, $17 \cdot 8 \mathrm{~g} / \mathrm{d}$ for controls, $v$. $27.7 \mathrm{~g} / \mathrm{d}$ for KNHANES). However, cases and controls had a higher tangerine intake than that reported by KNHANES $(38.6 \mathrm{~g} / \mathrm{d}$ for malignant cases, $44.8 \mathrm{~g} / \mathrm{d}$ for benign cases, $45 \cdot 1 \mathrm{~g} / \mathrm{d}$ for controls, $v .28 \cdot 2 \mathrm{~g} / \mathrm{d}$ for KNHANES). The level of vegetable consumption by Korean adults has been reported to be relatively high ${ }^{(30,31)}$. The amount of vegetables consumed per person per year in Korea in 2005 was relatively high at $695 \mathrm{~g}$ for Korea, almost twice that of the USA ( $344 \mathrm{~g}$ ) but lower than that of Greece $(807 \mathrm{~g})^{(32)}$. When the intake of fruits and vegetables was 
Table 3. Potential confounders according to quartile of intake of fruit, persimmons and tangerines among controls $† \ddagger$

\begin{tabular}{|c|c|c|c|c|c|c|c|c|c|c|c|c|c|c|c|}
\hline & \multicolumn{4}{|c|}{ Quartiles of daily total fruit intake } & \multirow[b]{2}{*}{$P$ for trend ${ }^{*}$} & \multicolumn{4}{|c|}{ Quartiles of daily persimmon intake } & \multirow[b]{2}{*}{$P$ for trend ${ }^{*}$} & \multicolumn{4}{|c|}{ Quartiles of daily tangerine intake } & \multirow[b]{2}{*}{$P$ for trend } \\
\hline & 1 st & 2nd & $3 r d$ & 4th & & 1 st & 2nd & $3 r d$ & 4th & & 1st & 2nd & 3 rd & 4th & \\
\hline Median (g) & $66 \cdot 4$ & $176 \cdot 1$ & 299.5 & $599 \cdot 2$ & & 0.0 & 3.4 & 7.9 & 31.5 & & $3 \cdot 3$ & $20 \cdot 0$ & $40 \cdot 0$ & $76 \cdot 8$ & \\
\hline Age (years) & $48 \cdot 1$ & 44.9 & 43.9 & 44.9 & 0.452 & 41.7 & $45 \cdot 3$ & $43 \cdot 2$ & 48.5 & 0.014 & $45 \cdot 3$ & $46 \cdot 7$ & 44.4 & 44.3 & 0.461 \\
\hline Menopause women (\%) & $37 \cdot 0$ & 54.3 & 39.4 & 38.0 & 0.372 & 40.3 & $45 \cdot 7$ & $42 \cdot 9$ & 38.2 & 0.809 & $40 \cdot 3$ & 47.5 & $41 \cdot 7$ & 38.0 & 0.436 \\
\hline Education (years) & $11 \cdot 2$ & $11 \cdot 6$ & $12 \cdot 8$ & $12 \cdot 3$ & 0.143 & $12 \cdot 4$ & $11 \cdot 7$ & $12 \cdot 4$ & $12 \cdot 0$ & 0.835 & $11 \cdot 0$ & 11.9 & $13 \cdot 3$ & 11.9 & 0.424 \\
\hline BMI $\left(\mathrm{kg} / \mathrm{m}^{2}\right)$ & $24 \cdot 2$ & $23 \cdot 1$ & $22 \cdot 9$ & $23 \cdot 4$ & 0.726 & $23 \cdot 6$ & $23 \cdot 8$ & $22 \cdot 9$ & 23.1 & 0.527 & $22 \cdot 9$ & $23 \cdot 3$ & $23 \cdot 6$ & $23 \cdot 4$ & 0.602 \\
\hline $\begin{array}{l}\text { Family history } \\
\text { of thyroid cancer (\%) }\end{array}$ & $4 \cdot 7$ & 0.0 & 0.0 & $5 \cdot 8$ & 0.598 & $0 \cdot 0$ & $5 \cdot 1$ & 0.0 & 1.6 & 0.865 & $5 \cdot 6$ & 0.0 & $4 \cdot 2$ & $2 \cdot 3$ & 0.946 \\
\hline Current smoker (\%) & $1 \cdot 1$ & 0.0 & 0.0 & 5.5 & 0.305 & $3 \cdot 2$ & $6 \cdot 4$ & 0.0 & 4.4 & 0.881 & $11 \cdot 2$ & $2 \cdot 8$ & 0.0 & $2 \cdot 5$ & 0.072 \\
\hline Current alcohol drinker (\%) & $50 \cdot 3$ & $46 \cdot 6$ & $38 \cdot 3$ & 34.3 & 0.134 & $45 \cdot 7$ & $43 \cdot 2$ & $56 \cdot 3$ & 33.0 & 0.174 & $61 \cdot 3$ & 41.6 & $27 \cdot 8$ & $42 \cdot 6$ & 0.208 \\
\hline $\begin{array}{l}\text { Regular exercise } \\
\text { (>22.5 MET-h/week, \%) }\end{array}$ & $11 \cdot 2$ & $12 \cdot 6$ & $21 \cdot 4$ & $21 \cdot 8$ & 0.266 & $10 \cdot 3$ & $17 \cdot 0$ & $20 \cdot 9$ & $15 \cdot 2$ & 0.904 & $16 \cdot 4$ & 13.5 & $15 \cdot 4$ & $16 \cdot 1$ & 0.800 \\
\hline Multivitamin user (\%) & $38 \cdot 1$ & $15 \cdot 6$ & $13 \cdot 1$ & $26 \cdot 9$ & 0.615 & $32 \cdot 1$ & $20 \cdot 4$ & $19 \cdot 1$ & $18 \cdot 0$ & 0.280 & 31.9 & $26 \cdot 3$ & $18 \cdot 0$ & $14 \cdot 0$ & 0.056 \\
\hline Parity (\%) & 79.5 & $77 \cdot 2$ & 83.5 & 88.0 & 0.111 & $80 \cdot 3$ & 77.9 & $87 \cdot 0$ & $86 \cdot 3$ & 0.189 & $75 \cdot 7$ & $82 \cdot 3$ & 84.7 & $88 \cdot 2$ & 0.044 \\
\hline Children $(n)$ & 1.5 & 1.9 & 1.9 & $2 \cdot 0$ & 0.122 & 1.9 & 1.6 & $2 \cdot 0$ & 1.9 & 0.441 & 1.7 & 1.8 & 1.9 & 1.9 & 0.367 \\
\hline $\begin{array}{l}\text { Oral contraceptive } \\
\text { use (ever, \%) }\end{array}$ & $21 \cdot 3$ & $26 \cdot 5$ & $16 \cdot 0$ & $16 \cdot 2$ & 0.482 & $21 \cdot 6$ & $17 \cdot 0$ & $24 \cdot 4$ & $20 \cdot 9$ & 0.955 & $21 \cdot 4$ & $16 \cdot 6$ & $25 \cdot 7$ & 20.5 & $0 \cdot 767$ \\
\hline Breast-feeding (ever, \%) & $60 \cdot 8$ & $70 \cdot 7$ & 68.5 & 74.5 & 0.207 & 58.5 & $66 \cdot 0$ & $70 \cdot 1$ & $74 \cdot 6$ & 0.088 & $72 \cdot 0$ & $65 \cdot 2$ & 74.9 & $70 \cdot 4$ & 0.540 \\
\hline $\begin{array}{l}\text { Used hormone } \\
\text { compound (ever, \%) }\end{array}$ & $22 \cdot 3$ & $22 \cdot 1$ & $16 \cdot 4$ & $18 \cdot 9$ & 0.399 & $37 \cdot 3$ & $20 \cdot 7$ & $17 \cdot 2$ & $13 \cdot 7$ & 0.067 & $24 \cdot 7$ & $23 \cdot 6$ & $12 \cdot 8$ & $19 \cdot 9$ & 0.648 \\
\hline Age at menarche (years) & $13 \cdot 9$ & 14.9 & $14 \cdot 8$ & $14 \cdot 3$ & 0.943 & $14 \cdot 3$ & $13 \cdot 9$ & $14 \cdot 9$ & 14.9 & 0.027 & $14 \cdot 7$ & 14.4 & $14 \cdot 3$ & $14 \cdot 6$ & 0.843 \\
\hline Age at first birth (years) & $26 \cdot 0$ & $25 \cdot 5$ & $25 \cdot 7$ & $26 \cdot 4$ & 0.431 & $26 \cdot 2$ & $25 \cdot 9$ & $26 \cdot 0$ & $25 \cdot 8$ & 0.762 & $25 \cdot 2$ & $25 \cdot 7$ & $26 \cdot 9$ & $25 \cdot 9$ & 0.627 \\
\hline Age at menopause (years) & $47 \cdot 7$ & $50 \cdot 2$ & 49.7 & $48 \cdot 8$ & 0.999 & 51.9 & $47 \cdot 3$ & $50 \cdot 2$ & 49.6 & 0.677 & $50 \cdot 3$ & $48 \cdot 8$ & $49 \cdot 8$ & $49 \cdot 1$ & 0.811 \\
\hline Energy intake $(\mathrm{kJ} / \mathrm{d})$ & $7060 \cdot 1$ & 7567.4 & $8757 \cdot 3$ & 9971.1 & $<.0001$ & 8538.0 & $7690 \cdot 0$ & 8070.5 & 9273.0 & 0.135 & $6756 \cdot 7$ & $8615 \cdot 9$ & $8632 \cdot 6$ & $9195 \cdot 1$ & 0.004 \\
\hline$\beta$-Carotene $(\mu \mathrm{g} / \mathrm{d})$ & $3019 \cdot 9$ & $3805 \cdot 3$ & $4924 \cdot 8$ & $5523 \cdot 1$ & 0.021 & $4352 \cdot 7$ & $3197 \cdot 7$ & $5820 \cdot 6$ & $4649 \cdot 7$ & 0.479 & $3387 \cdot 3$ & $4894 \cdot 1$ & 4402.5 & $4619 \cdot 9$ & 0.566 \\
\hline Vitamin C intake (mg/d) & 88.6 & $122 \cdot 7$ & $155 \cdot 8$ & $206 \cdot 0$ & $<.0001$ & $121 \cdot 0$ & 114.7 & $168 \cdot 6$ & $178 \cdot 1$ & 0.000 & $103 \cdot 9$ & $126 \cdot 6$ & 153.5 & $192 \cdot 3$ & 0.039 \\
\hline Folate intake $(\mu \mathrm{g} / \mathrm{d})$ & $221 \cdot 2$ & 258.9 & $285 \cdot 6$ & $323 \cdot 6$ & 0.001 & 252.9 & $248 \cdot 0$ & $326 \cdot 2$ & $283 \cdot 3$ & 0.345 & 244.7 & $280 \cdot 3$ & $273 \cdot 2$ & 294.3 & 0.191 \\
\hline Vitamin E intake (mg/d) & $8 \cdot 0$ & 9.9 & 8.5 & $10 \cdot 0$ & 0.145 & $9 \cdot 4$ & $8 \cdot 1$ & $10 \cdot 1$ & $9 \cdot 2$ & 0.729 & $9 \cdot 0$ & $9 \cdot 2$ & 8.9 & $9 \cdot 4$ & 0.657 \\
\hline Na intake $(\mathrm{mg} / \mathrm{d})$ & $3790 \cdot 9$ & $4151 \cdot 8$ & 4058.5 & $4323 \cdot 2$ & 0.247 & $3706 \cdot 1$ & $4018 \cdot 2$ & $4569 \cdot 0$ & $4108 \cdot 4$ & 0.641 & $3897 \cdot 6$ & 4350.5 & $3789 \cdot 8$ & $4198 \cdot 1$ & 0.802 \\
\hline
\end{tabular}

\section{MET, metabolic equivalent.}

* $P$-values for trends were determined by the general linear model for continuous variables and by the Cochran-Mantel-Haenszel test for categorical variables.

$\dagger$ All results except median and age were adjusted for age, and all nutrient intakes are total energy-adjusted values.

‡ Values are expressed as mean or percentage according to quartile of fruit and vegetable intake. 
Table 4. Thyroid cancer according to quartiles of vegetable and fruit intake in multiple logistic regression models (Odds ratios and $95 \%$ confidence intervals)

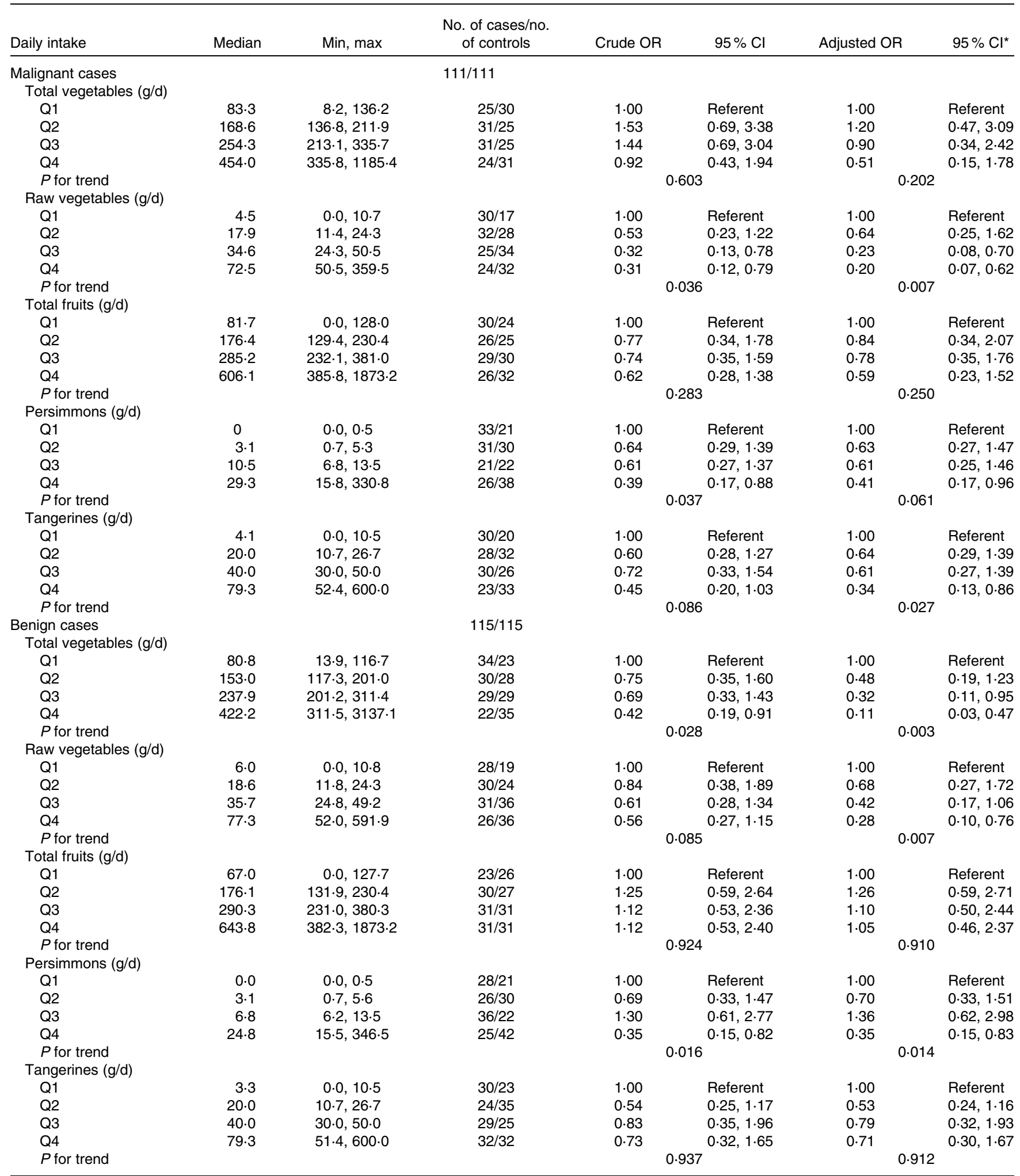

Min, minimum; max, maximum.

${ }^{*}$ All adjusted OR models included parity (yes/no), energy (quartile) in the malignant cancer model. Energy (quartile) was adjusted for in the benign cancer model. The model for total vegetables was additionally adjusted by $\mathrm{Na}$ intake (quartile). The model for raw vegetables was additionally adjusted for $\mathrm{Na}$ intake (quartile) and vitamin $\mathrm{E}$ intake (quartile). The model for persimmons was additionally adjusted for age at menarche (years). The model for tangerines was additionally adjusted for parity (yes/no). 
Table 5. Thyroid cancer according to quartiles of the average frequency of vegetable and fruit consumption in multiple logistic regression models (Odds ratios and $95 \%$ confidence intervals)

\begin{tabular}{|c|c|c|c|c|c|c|c|}
\hline Average frequency & Median & Min, max & $\begin{array}{l}\text { No. of cases/no. } \\
\text { of controls }\end{array}$ & Crude OR & $95 \% \mathrm{Cl}$ & Adjusted OR & $95 \% \mathrm{Cl}^{*}$ \\
\hline Malignant cases & & & $111 / 111$ & & & & \\
\hline \multicolumn{8}{|c|}{ Total vegetables (times/week) } \\
\hline Q1 & $17 \cdot 5$ & $3 \cdot 8,22 \cdot 7$ & $21 / 34$ & 1.00 & Referent & 1.00 & Referent \\
\hline Q2 & $27 \cdot 7$ & $23 \cdot 1,31 \cdot 8$ & $37 / 19$ & 2.75 & $1.30,5.83$ & 2.54 & $1 \cdot 11,5 \cdot 80$ \\
\hline Q3 & $37 \cdot 4$ & $32 \cdot 2,45 \cdot 1$ & $27 / 29$ & 1.32 & $0.61,2 \cdot 86$ & 1.19 & $0.49,2.90$ \\
\hline Q4 & 58.4 & $45 \cdot 6,92 \cdot 0$ & $26 / 29$ & 1.30 & $0.59,2.87$ & $1 \cdot 24$ & $0.43,3.59$ \\
\hline$P$ for trend & & & & \multicolumn{2}{|c|}{0.921} & \multicolumn{2}{|c|}{0.924} \\
\hline \multicolumn{8}{|c|}{ Raw vegetables (times/week) } \\
\hline Q1 & 0.8 & $0 \cdot 0,2 \cdot 4$ & $30 / 25$ & 1.00 & Referent & 1.00 & Referent \\
\hline Q2 & $3 \cdot 2$ & $2 \cdot 4,3 \cdot 9$ & $31 / 25$ & 0.94 & $0.44,2.02$ & 0.76 & $0.33,1.79$ \\
\hline Q3 & $5 \cdot 2$ & $3 \cdot 9,6 \cdot 7$ & $29 / 27$ & 0.81 & $0.36,1.84$ & 0.66 & $0.25,1.73$ \\
\hline Q4 & $10 \cdot 0$ & $6 \cdot 8,28 \cdot 4$ & $21 / 34$ & 0.48 & $0.21,1 \cdot 11$ & 0.28 & $0.10,0.78$ \\
\hline$P$ for trend & & & & \multicolumn{2}{|c|}{0.050} & \multicolumn{2}{|c|}{0.009} \\
\hline \multicolumn{8}{|c|}{ Total fruits (times/week) } \\
\hline Q1 & $2 \cdot 7$ & $0 \cdot 0,4 \cdot 3$ & $29 / 26$ & 1.00 & Referent & 1.00 & Referent \\
\hline Q2 & $6 \cdot 2$ & $4 \cdot 3,7 \cdot 7$ & $31 / 25$ & $1 \cdot 13$ & $0.50,2.52$ & 1.31 & $0.55,3.10$ \\
\hline Q3 & $9 \cdot 7$ & $7 \cdot 7,12 \cdot 0$ & $26 / 30$ & 0.75 & $0.35,1.65$ & 0.80 & $0.35,1.85$ \\
\hline Q4 & $16 \cdot 1$ & $12 \cdot 0,44 \cdot 9$ & $25 / 30$ & 0.75 & $0.35,1.62$ & 0.73 & $0.30,1.78$ \\
\hline$P$ for trend & & & & \multicolumn{2}{|c|}{0.318} & \multicolumn{2}{|c|}{0.267} \\
\hline \multicolumn{4}{|c|}{ Persimmons (times/week) } & & & & \\
\hline Q1 & 0.0 & $0.0,0.0$ & $33 / 22$ & 1.00 & Referent & $1 \cdot 00$ & Referent \\
\hline Q2 & 0.3 & $0.1,0.3$ & $30 / 29$ & 0.71 & $0.34,1.51$ & 0.61 & $0.26,1.39$ \\
\hline Q3 & 0.4 & $0.3,0.6$ & $24 / 24$ & 0.67 & $0.31,1.45$ & 0.76 & $0.33,1.78$ \\
\hline Q4 & $1 \cdot 2$ & $0 \cdot 9,5 \cdot 3$ & $24 / 36$ & 0.44 & $0.20,0.94$ & 0.44 & $0.20,0.99$ \\
\hline$P$ for trend & & & & \multicolumn{2}{|c|}{0.040} & \multicolumn{2}{|c|}{0.060} \\
\hline \multicolumn{4}{|c|}{ Tangerines (times/week) } & & & & \\
\hline Q1 & 0.3 & $0.0,0.4$ & $39 / 27$ & 1.00 & Referent & 1.00 & Referent \\
\hline Q2 & 0.9 & $0.5,0.9$ & $22 / 20$ & 0.77 & $0.33,1.76$ & 0.83 & $0.35,1.97$ \\
\hline Q3 & 1.2 & $0.9,1.4$ & $24 / 36$ & 0.47 & $0.23,0.96$ & 0.41 & $0.19,0.88$ \\
\hline Q4 & 1.8 & $1.5,5 \cdot 3$ & $26 / 28$ & 0.60 & $0.27,1.30$ & 0.50 & $0.21,1.19$ \\
\hline$P$ for trend & & & & \multicolumn{2}{|c|}{0.112} & & \\
\hline Benign cases & & & & & & & \\
\hline Total vegetables & & & & & & & \\
\hline Q1 & $14 \cdot 7$ & $3 \cdot 2,20 \cdot 6$ & $30 / 27$ & 1.00 & Referent & 1.00 & Referent \\
\hline Q2 & $26 \cdot 0$ & $20 \cdot 8,31 \cdot 3$ & $23 / 35$ & 1.81 & $0.83,3.96$ & 1.84 & $0.83,4.06$ \\
\hline Q3 & $36 \cdot 2$ & $31 \cdot 7,45 \cdot 8$ & $33 / 25$ & 0.76 & $0.35,1.69$ & 0.71 & $0.28,1.78$ \\
\hline Q4 & 58.0 & $45 \cdot 9,101 \cdot 4$ & $29 / 28$ & 1.03 & $0.45,2.32$ & 0.94 & $0.35,2.52$ \\
\hline$P$ for trend & & & & & & & \\
\hline Raw vegetables ( & & & & & & & \\
\hline Q1 & 1.4 & $0 \cdot 0,2 \cdot 4$ & $33 / 24$ & 1.00 & Referent & 1.00 & Referent \\
\hline Q2 & $3 \cdot 1$ & $2.4,3.9$ & $29 / 29$ & 0.72 & $0.33,1.59$ & 0.57 & $0.24,1.36$ \\
\hline Q3 & $5 \cdot 6$ & $4 \cdot 0,7 \cdot 3$ & $27 / 31$ & 0.68 & $0.34,1.37$ & 0.45 & $0.19,1.05$ \\
\hline Q4 & $10 \cdot 7$ & $7 \cdot 5,29.5$ & $26 / 31$ & 0.67 & $0.34,1.32$ & 0.38 & $0.16,0.91$ \\
\hline$P$ for trend & & & & & & & \\
\hline Total fruits (times/ & & & & & & & \\
\hline Q1 & 3.0 & $0.0,4 \cdot 6$ & $28 / 29$ & 1.00 & Referent & 1.00 & Referent \\
\hline Q2 & 5.9 & $4 \cdot 7,7 \cdot 3$ & $32 / 26$ & 1.27 & $0.59,2.73$ & 1.30 & $0.58,2.89$ \\
\hline Q3 & $9 \cdot 7$ & $7 \cdot 3,12 \cdot 2$ & $25 / 33$ & 0.80 & $0.38,1.71$ & 0.82 & $0.38,1.80$ \\
\hline Q4 & $18 \cdot 6$ & $12 \cdot 2,44 \cdot 9$ & $30 / 27$ & 1.14 & $0.53,2.46$ & 1.09 & $0.46,2.59$ \\
\hline$P$ for trend & & & & & & & \\
\hline Persimmons (time & & & & & & & \\
\hline Q1 & 0.0 & $0.0,0.1$ & $33 / 25$ & 1.00 & Referent & 1.00 & Referent \\
\hline Q2 & 0.3 & $0.1,0.3$ & $26 / 29$ & 0.67 & $0.33,1.38$ & 0.67 & $0.32,1.37$ \\
\hline Q3 & 0.4 & $0.4,0.6$ & $33 / 22$ & $1 \cdot 28$ & $0.59,2.74$ & 1.31 & $0.59,2.92$ \\
\hline Q4 & $1 \cdot 2$ & $0 \cdot 9,5 \cdot 3$ & $23 / 39$ & 0.35 & $0.15,0.81$ & 0.33 & $0.14,0.79$ \\
\hline$P$ for trend & & & & & & & \\
\hline Tangerines (times & & & & & & & \\
\hline Q1 & 0.3 & $0.0,0.4$ & $34 / 27$ & 1.00 & Referent & 1.00 & Referent \\
\hline Q2 & 0.9 & $0.5,0.9$ & $21 / 20$ & 0.50 & $0.22,1 \cdot 13$ & 0.50 & $0.22,1.14$ \\
\hline Q3 & $1 \cdot 2$ & $1 \cdot 2,1 \cdot 5$ & $28 / 36$ & 0.94 & $0.43,2.08$ & 0.91 & $0.40,2.07$ \\
\hline Q4 & 1.8 & $1.5,7 \cdot 0$ & $32 / 28$ & 0.95 & $0.43,2 \cdot 11$ & 0.92 & $0.40,2.12$ \\
\hline$P$ for trend & & & & & & & \\
\hline
\end{tabular}

Min, minimum; max, maximum.

${ }^{*}$ All adjusted OR models included parity (yes/no), energy (quartile) for the malignant cancer model. Energy (quartile) was adjusted for in the benign cancer model. The model for frequency of consumption of total vegetables was additionally adjusted for $\mathrm{Na}$ intake (quartile). The model for frequency of consumption of raw vegetables was additionally adjusted for $\mathrm{Na}$ intake (quartile) and vitamin $\mathrm{E}$ intake (quartile). The model for frequency of consumption of persimmons was additionally adjusted for age at menarche (years). The model for tangerines was additionally adjusted for parity (yes/no). 
combined $(503.4 \mathrm{~g} / \mathrm{d}$ in the fourth KNHANES), the intake by Koreans based on national surveys was higher than that of Europeans ${ }^{(33,34)}$.

Several meta-analyses of the association between fruit and vegetable intake and the risk of cancers including breast cancer $^{(35)}$, colon cancer $^{(36)}$, oral cancer $^{(37)}$ and gastric cancer $^{(38)}$ have found that vegetable intakes were inversely associated with the risk of breast cancer ${ }^{(35)}$, oral cancer ${ }^{(37)}$ and gastric cancer ${ }^{(38)}$, but the site-specific associations of colon cancer were not consistent ${ }^{(36)}$ and that the fruit intakes were significantly related to oral cancer ${ }^{(37)}$ and gastric cancer risk $^{(38)}$. Fruits and vegetables may exert their protective effects via antioxidant mechanisms, by serving as substrates for the formation of anti-neoplastic agents, by inhibiting nitrosamine formation, and/or by altering hormone metabolism, among other possible mechanisms ${ }^{(21,39)}$. Furthermore, multiple substances present in fruits and vegetables such as antioxidant vitamins ( $\beta$-carotene, vitamin $\mathrm{A}$, vitamin $\mathrm{E}$, vitamin $\mathrm{C}$ ), dietary fibres, micronutrients and other phytochemicals may protect against cancer ${ }^{(40)}$. Several studies have also investigated the association between thyroid cancer risk and consumption of vegetables, especially in western countries ${ }^{(4,9-12,16)}$. These studies reported an inverse association between thyroid cancer risk and raw vegetable consumption ${ }^{(4,10-12)}$. In the present study, we focused on the effect of raw vegetables to obtain additional information about the inverse, doseresponse associations between the amount and frequency of raw vegetable intake and thyroid cancer risk (more than $24.3 \mathrm{~g} / \mathrm{d}$ ) in malignant and benign cases. However, unlike the intake of raw vegetables, the intake of total vegetables and the frequency of vegetable consumption were not associated with malignant thyroid cancer. More than $50 \%$ of the total vegetables consumed in Korea are pickled or cooked based on the results of the third KNHANES in 2005; the consumption of pickled and cooked vegetables may attenuate the effects of raw vegetables, possibly due to the carcinogenic effect of salt in pickled vegetables ${ }^{(25)}$ and/or the destruction of the anti-carcinogenic activity of raw vegetables by processing and storage under acidic and oxygen-rich conditions ${ }^{(41)}$.

No consistent association between fruit intake and thyroid cancer risk has been found in previous studies. Markaki et $a l .{ }^{(9)}$ reported that high fruit consumption had a protective effect on thyroid cancer risk (OR $0.68, P=0 \cdot 01$ ). In contrast, studies in Kuwait ${ }^{(12)}$ and Northern Europe ${ }^{(10)}$ showed no association between the amount of fruit consumed and thyroid cancer risk. We found no significant association between total fruit intake and thyroid cancer risk but among fruits, persimmon and tangerine intakes were inversely associated with thyroid cancer risk. Diospyros kaki Thunb. (Ebenaceae), more commonly known as persimmon, is widely distributed in East Asian countries such as Korea, Japan and China ${ }^{(42)}$. Persimmon contains many bioactive agents such as flavonoids, tannins, carotenoids, antioxidant vitamins and minerals ${ }^{(43,44)}$ that may mediate anti-carcinogenic processes. Furthermore, the anti-oxidative activity of persimmon has been examined both in vitro ${ }^{(44-47)}$ and in vivo ${ }^{(45)}$. Among the extracts of persimmon, tannins in particular may increase catalase and superoxide dismutase activity, thereby reducing oxidative damage to cells ${ }^{(45)}$. As another explanation for the anti-carcinogenic effects of persimmon, 24-hydroxyursolic acid from persimmon may inhibit cell proliferation by activating AMP-activated protein kinase signalling, resulting in growth inhibition and cell apoptosis $^{(46)}$. However, there is very limited evidence available regarding the association between persimmon intake and cancer risk in epidemiological studies ${ }^{(48)}$. In the present study, both the amount of persimmon consumed (more than $15 \cdot 8 \mathrm{~g} / \mathrm{d}$ ) and the frequency of consumption (approximately once per d) had a significant inverse relationship with thyroid cancer risk. These results are consistent with those reported by a case-control study in China; the authors of that study reported that persimmon intake significantly reduced breast cancer risk (OR 0.60; 95\% CI 0.42, 0.86; $P$ for trend $=0.006)^{(48)}$. Tangerine (Citrus reticulate Blanco) is a citrus fruit that is a good source of bioactive compounds such as flavonoids, vitamin C, carotenoids, limonene and citric acid ${ }^{(21)}$. Citrus flavonoids are known to have strong anti-proliferative activities in human cancer cells ${ }^{(49)}$. Citrus flavonoids may function as anticancer agents by inhibiting enzymes such as protein kinases involved in mitogenic signal transduction ${ }^{(50)}$. Epidemiological studies have been conducted in the past to determine if there is a relationship between citrus fruit intake, including tangerine intake, and thyroid cancer risk ${ }^{(10)}$, colon, rectum cancer risk ${ }^{(51)}$ and breast cancer risk ${ }^{(48,51)}$. However, no significant negative association was observed in any of these previous studies ${ }^{(48,51)}$.

The present study had several limitations. First, it was a hospital-based case-control study, and thus, the results may not be generalisable to the general population ${ }^{(52)}$. Second, recall bias is one of the important potential biases in a case-control study. The differential recall between cases and controls may induce biased results ${ }^{(53)}$. However, in the present study, almost all cases were interviewed before diagnosis so that differential recall biases may not be substantial. Third, the sample size was not sufficient to draw definitive conclusions and we were not able to analyse the differences in risk factors according to the subtype of thyroid cancer (papillary, follicular, medullary, anaplastic). The number of pairs assuming $\alpha=0.05, \beta=0.10$ and an OR of 2.0 (or 0.5 ) was 281 pairs $^{(54)}$. However, the final sample size was smaller than the calculated number. Therefore, a weak relationship (OR $<2.0$ or $0.5<$ OR $<1.0$ ) may not have been detected in the present study. Fourth, although the semiquantitative FFQ has been validated in previous studies, we did not perform the additional validity-reliability study for the modified version and for food items. Fifth, among the non-dietary risk factors for thyroid cancer, the best-established cause of thyroid cancer is exposure to ionising radiation, particularly during early childhood ${ }^{(1,4)}$. We could not measure the extent of radiation exposure. In future studies, radiation in everyday life including medical radiation needs to be assessed and to be analysed for the association with thyroid cancer. Sixth, we could not examine the association between benign thyroid nodules or adenomas and malignant thyroid cancer risk in the present study, because we recruited controls who did not have thyroid nodules or thyroid hormone diseases. In the analyses, after excluding pairs with history of any thyroid disease in cases (twenty-nine pairs in malignant cancer and forty-three 
pairs in benign thyroid nodules or adenomas), the association between fruit and vegetable intake and thyroid cancer risk did not substantially change. To the best of our knowledge, ours is the first study to focus on benign thyroid cases and to use controls without any nodules in the thyroid gland.

The findings in the present study suggest that high consumption of raw vegetables, persimmons and tangerines may decrease thyroid cancer risk. In addition, consumption of raw vegetables and these fruits may help prevent thyroid cancer. However, our findings need to be confirmed in a large-scale cohort study.

\section{Acknowledgements}

The present study was supported by the Korean Ministry of Science and Technology (grant nos M10418020002-08N180200210 and M10418020002-09N1802-00210). The authors wish to thank all subjects for their dedication and commitment. M. K. K. designed and supervised the execution of the study. S. K. J. performed the data analyses and wrote the manuscript with K. K. In addition, K. T. and G. K. contributed to the data preparation. All authors participated in the interpretation of the results and the editing of the manuscript. None of the authors had a personal or financial conflict of interest.

\section{References}

1. DeLellis RA (2004) Pathology and Genetics of Tumours of Endocrine Organs, vol. 8. Geneva: World Health Organization.

2. Ferlay J, Shin H, Bray F, et al. (2010) Globocan 2008, Cancer Incidence and Mortality Worldwide. Lyon, France: International Agency for Research on Cancer.

3. The Korea Central Cancer Registry (2010) Annual Report of Cancer Statistics in Korea in 2008: Ministry of Health and Welfare. Seoul, South Korea: The Korea Central Cancer Registry.

4. Dal Maso L, Bosetti C, La Vecchia C, et al. (2009) Risk factors for thyroid cancer: an epidemiological review focused on nutritional factors. Cancer Causes Control 20, 75-86.

5. Franceschi S, Preston-Martin S, Maso LD, et al. (1999) A pooled analysis of case-control studies of thyroid cancer. IV. Benign thyroid diseases. Cancer Causes Control 10, 583-595.

6. Elisei R, Romei C, Vorontsova T, et al. (2001) RET/PTC rearrangements in thyroid nodules: studies in irradiated and not irradiated, malignant and benign thyroid lesions in children and adults. J Clin Endocrinol Metab 86, $3211-3216$

7. Kondo T, Ezzat S \& Asa SL (2006) Pathogenetic mechanisms in thyroid follicular-cell neoplasia. Nat Rev Cancer 6, 292-306.

8. Wong FL, Ron E, Gieriowski T, et al. (1996) Benign thyroid tumors: general risk factors and their effects on radiation risk estimation. Am J Epidemiol 144, 728-733.

9. Markaki I, Linos D \& Linos A (2003) The influence of dietary patterns on the development of thyroid cancer. Eur J Cancer 39, 1912-1919.

10. Galanti MR, Hansson L, Bergstrom R, et al. (1997) Diet and the risk of papillary and follicular thyroid carcinoma: a population-based case-control study in Sweden and Norway. Cancer Causes Control 8, 205-214.
11. Bosetti C, Negri E, Kolonel L, et al. (2002) A pooled analysis of case-control studies of thyroid cancer. VII. Cruciferous and other vegetables (International). Cancer Causes Control 13, 765-775.

12. Memon A, Varghese A \& Suresh A (2002) Benign thyroid disease and dietary factors in thyroid cancer: a case-control study in Kuwait. Br J Cancer 86, 1745-1750.

13. Truong T, Baron-Dubourdieu D, Rougier Y, et al. (2010) Role of dietary iodine and cruciferous vegetables in thyroid cancer: a countrywide case-control study in New Caledonia. Cancer Causes Control 21, 1183-1192.

14. Bosetti C, Kolonel L, Negri E, et al. (2001) A pooled analysis of case-control studies of thyroid cancer. VI. Fish and shellfish consumption. Cancer Causes Control 12, 375-382.

15. Horn-Ross PL, Morris JS, Lee M, et al. (2001) Iodine and thyroid cancer risk among women in a multiethnic population. Cancer Epidemiol Biomarkers Prev 10, 979-985.

16. Mack WJ, Preston-Martin S, Bernstein L, et al. (2002) Lifestyle and other risk factors for thyroid cancer in Los Angeles County females. Ann Epidemiol 12, 395-401.

17. Randi G, Ferraroni M, Talamini R, et al. (2008) Glycemic index, glycemic load and thyroid cancer risk. Ann Oncol 19, 380-383.

18. D'Avanzo B, Ron E, Vecchia CL, et al. (1997) Selected micronutrient intake and thyroid carcinoma risk. Cancer $\mathbf{7 9}$, 2186-2192.

19. Kilfoy B, Zhang Y, Park Y, et al. (2011) Dietary nitrate and nitrite and the risk of thyroid cancer in the NIH-AARP Diet and Health Study. Int J cancer 129, 160-172.

20. Ward MH, Kilfoy BA, Weyer PJ, et al. (2010) Nitrate intake and the risk of thyroid cancer and thyroid disease. Epidemiology 21, 389-395.

21. Vainio H \& Bianchini F (2003) IARC Handbooks of Cancer Prevention. Volume 8: Fruit and Vegetables. Lyon, France: IARC Press, International Agency for Research on Cancer.

22. Marmot M, Atinmo T, Byers T, et al. (2007) Food, Nutrition, Physical Activity, and the Prevention of Cancer: A Global Perspective. Washington, DC: World Cancer Research Fund/ American Institute for Cancer Research.

23. Kim HJ, Lim SY, Lee JS, et al. (2010) Fresh and pickled vegetable consumption and gastric cancer in Japanese and Korean populations: a meta analysis of observational studies. Cancer Sci 101, 508-516.

24. Yu H, Hwang JY, Ro J, et al. (2010) Vegetables, but not pickled vegetables, are negatively associated with the risk of breast cancer. Nutr Cancer 62, 443-453.

25. Ying WZ \& Sanders PW (2002) Dietary salt intake activates MAP kinases in the rat kidney. FASEB J 16, 1683-1684.

26. Kaur C \& Kapoor H (2001) Antioxidants in fruits and vegetables - the millennium's health. Int J Food Sci Technol 36, $703-725$.

27. Kim M, Lee S \& Ahn Y (1996) Reproducibility and validity of a self-administered semiquantitative food frequency questionnaire among middle-aged men in Seoul. Korean $J$ Community Nutr 1, 376-394.

28. Willett WC (1998) Nutritional Epidemiology. New York, NY: Oxford Universtiy Press.

29. The Korean Nutrition Society (2003) Foods and Nutrients Database of Computer Aided Nutritional Analysis Program Version 2.0. Seoul, South Korea: The Korean Nutrition Society.

30. Popkin B (2000) The nutrition transition in South Korea Am J Clin Nutr 71, 44-53.

31. Lee MJ, Popkin BM \& Kim S (2002) The unique aspects of the nutrition transition in South Korea: the retention of 
healthful elements in their traditional diet. Public Health Nutr 5, 197-204.

32. Korea Rural Economic Institute (2006) Food Supply and Demand Table. Seoul, South Korea: Korea Rural Economic Institute.

33. Department for Environment Rural Affairs (2007) Family Food in 2005-06: [A Report on the 2005-06 Expenditure and Food Survey]. London: The Stationery Office.

34. Joffe M \& Robertson A (2001) The potential contribution of increased vegetable and fruit consumption to health gain in the European Union. Public Health Nutr 4, 893-901.

35. Gandini S, Merzenich H, Robertson C, et al. (2000) Meta-analysis of studies on breast cancer risk and diet: the role of fruit and vegetable consumption and the intake of associated micronutrients. Eur J Cancer 36, 636-646.

36. Koushik A, Hunter DJ, Spiegelman D, et al. (2007) Fruits, vegetables, and colon cancer risk in a pooled analysis of 14 cohort studies. J Natl Cancer Inst 99, 1471-1483.

37. Pavia M, Pileggi C, Nobile CGA, et al. (2006) Association between fruit and vegetable consumption and oral cancer: a meta-analysis of observational studies. Am J Clin Nutr 83, 1126-1134.

38. Lunet N, Valbuena C, Vieira AL, et al. (2007) Fruit and vegetable consumption and gastric cancer by location and histological type: case-control and meta-analysis. Eur $J$ Cancer Prev 16, 312-327.

39. Steinmetz KA \& Potter JD (1991) Vegetables, fruit, and cancer. II. Mechanisms. Cancer Causes Control 2, 427-442.

40. La Vecchia C, Altieri A \& Tavani A (2001) Vegetables, fruit, antioxidants and cancer: a review of Italian studies. Eur J Nutr 40, 261-267.

41. Kaur C \& Kapoor HC (2001) Antioxidants in fruits and vegetables-the millennium's health. Int J Food Sci Technol 36, $703-725$.

42. Sakanaka S, Tachibana Y \& Okada Y (2005) Preparation and antioxidant properties of extracts of Japanese persimmon leaf tea (kakinoha-cha). Food Chem 89, 569-575.
43. Mallavadhani U, Panda AK \& Rao Y (1998) Pharmacology and chemotaxonomy of Diospyros. Phytochemistry $\mathbf{4 9}$, 901-951.

44. Kawase M, Motohashi N, Satoh K, et al. (2003) Biological activity of persimmon (Diospyros kaki) peel extracts. Phytother Res 17, 495-500.

45. Ahn HS, Jeon TI, Lee JY, et al. (2002) Antioxidative activity of persimmon and grape seed extract: in vitro and in vivo. Nutr Res 22, 1265-1273.

46. Khanal P, Oh WK, Thuong PT, et al. (2010) 24-Hydroxyursolic acid from the leaves of the Diospyros kaki (persimmon) induces apoptosis by activation of AMP-activated protein kinase. Planta Med 76, 689-693.

47. Jang IC, Jo EK, Bae MS, et al. (2010) Antioxidant and antigenotoxic activities of different parts of persimmon (Diospyros $k a k i$ cv. Fuyu) fruit. J Med Plant Res 4, 155-160.

48. Shannon J, Ray R, Wu C, et al. (2005) Food and botanical groupings and risk of breast cancer: a case-control study in Shanghai, China. Cancer Epidemiol Biomarkers Prev 14, $81-90$.

49. Manthey JA \& Guthrie N (2002) Antiproliferative activities of citrus flavonoids against six human cancer cell lines. J Agric Food Chem 50, 5837-5843.

50. Manthey JA, Guthrie N \& Grohmann K (2001) Biological properties of citrus flavonoids pertaining to cancer and inflammation. Curr Med Chem 8, 135-153.

51. Franceschi S, Parpinel M, La Vecchia C, et al. (1998) Role of different types of vegetables and fruit in the prevention of cancer of the colon, rectum, and breast. Epidemiology 9, $338-341$.

52. Breslow NE \& Day NE (1980) Statistical Methods in Cancer Research, vol. 32. Lyon: IARC.

53. Gordis L (2004) Epidemiology, 3rd ed. Philadelphia, PA: WB Saunders.

54. Schlesselman JJ \& Stolley PD (1982) Case-control Studies: Design, Conduct, Analysis. New York, NY: Oxford University Press. 